\title{
COPD Overdiagnosis and Its Effect on 30-Day Hospital Readmission Rates
}

\author{
Richard D Rice, Xiaozhen Han, Xiaofeng Wang, and Mohammed J Al-Jaghbeer
}

\begin{abstract}
BACKGROUND: Although specific guidelines exist for diagnosing COPD on the basis of spirometry testing data $\left(\mathrm{FEV}_{\mathbf{1}} / \mathrm{FVC}<\mathbf{0 . 7 0}\right.$ or above the lower limit of normal), the literature suggests that overdiagnosis is common. Whether overdiagnosis increases 30-d readmission rates has not yet been explored. The objective of this study was to determine the prevalence of COPD overdiagnosis and its effect on 30-d hospital readmission rates in our institution. METHODS: We retrospectively identified all subjects who were coded with a COPD hospital discharge in 2018 at Cleveland Clinic main campus and had spirometry data available, including FEV $_{1}$ and FVC. FEV $/$ FVC was calculated and compared with the predicted lower limit of normal values. Hospital discharge diagnosis and 30-d hospital readmission data were captured along with comorbidities and other demographics. RESULTS: In 2018, there were 424 hospital discharges with a COPD diagnosis with spirometry testing available. Of these subjects, $124(29 \%)$ were overdiagnosed in the lower limit of normal group and $99(23.3 \%)$ were in the $\geq 0.70$ group. One hundred subjects $(23.6 \%)$ had a 30-d hospital readmission. Of these subjects, 35 had $\mathrm{FEV}_{1} / \mathrm{FVC}$ that was greater than their predicted lower limit of normal on spirometry. Of the 324 subjects who were not readmitted within $30 \mathrm{~d}, 89$ (27.5\%) had $\mathrm{FEV}_{1} / \mathrm{FVC}$ greater than the lower limit of normal. If the 35 readmitted subjects had not been coded with COPD, the 30-d readmission rate would have decreased significantly from $23.6 \%$ to $16.7 \%$ (100 of 424 vs 65 of $389, P=.01)$. Even if all of the 124 subjects who had pulmonary function test data greater than the lower limit of normal had not been counted, the readmission rate would still have decreased from $23.6 \%$ to $21.7 \%$, but this was not significant (from 100 of 424 to 65 of $300, P=.3$ ). CONCLUSIONS: COPD was overdiagnosed in our cohort of subjects; this was true whether the $\mathrm{FEV}_{1} / \mathrm{FVC}<0.70$ standard or the lower limit of normal standard was used. Furthermore, this overdiagnosis artificially inflated the 30-d readmission rate. These results illustrate the caution providers should use when making a COPD diagnosis. Key words: COPD; spirometry; readmission; overdiagnosis. [Respir Care 2021;66(1):11-17. (C) 2021 Daedalus Enterprises]
\end{abstract}

\section{Introduction}

COPD is a common cause of significant mortality and morbidity in the United States and across the world. ${ }^{1-3}$ It carries a large financial burden that is mostly attributed to

\footnotetext{
Mr Rice and Dr Al-Jaghbeer are affiliated with the Respiratory Institute, Cleveland Clinic Main Campus, Cleveland, Ohio. Mr Han and Dr Wang are affiliated with the Department of Quantitative Health Sciences, Cleveland Clinic Main Campus, Cleveland, Ohio.
}

Mr Rice presented a version of this work as an Editors' Choice abstract at AARC Congress 2019, held November 9-12, 2019, in New Orleans, Louisiana.

The authors have disclosed no conflicts of interest. the rate of exacerbations and hospital readmissions. In the United States alone, total medical costs are estimated at $\$ 73$ billion annually. ${ }^{4}$ The average COPD 30-d hospital readmission rate for those on Medicare is approximately $22.6 \%,{ }^{5}$ and readmissions are associated with poor outcomes. ${ }^{6}$ As a result, COPD was added as one of the conditions included under the Medicare Hospital Readmissions Reduction Program. ${ }^{7}$

\footnotetext{
Correspondence: Richard D Rice RRT MEd, Respiratory Institute, Cleveland Clinic, Mail code A-90, 9500 Euclid Ave, Cleveland, OH 44195. E-mail: ricer@ccf.org.
}

DOI: $10.4187 /$ respcare. 07536 
According to the Global Initiative for Obstructive Lung Disease (GOLD) guidelines, COPD should be considered

See the Related Editorial on Page 173

in symptomatic patients, and spirometry testing is required to confirm diagnosis. ${ }^{8}$ The group defines COPD as a postbronchodilator $\mathrm{FEV}_{1} / \mathrm{FVC}<0.70$. Alternatively, COPD can be diagnosed when $\mathrm{FEV}_{1} / \mathrm{FVC}$ is less than the lower limit of normal. However, even with these specific guidelines in place, COPD overdiagnosis can occur. Up to a third of patients admitted to the hospital with a diagnosis of COPD exacerbation may have an inaccurate diagnosis based on spirometry testing. ${ }^{9}$ Overdiagnosis is also common in patients with a history of smoking, chronic cough, and bronchitis..$^{10-14}$

There are many health and financial implications of COPD overdiagnosis. While it may be beneficial to prescribe respiratory medications for those who are symptomatic, those who are overdiagnosed may be unnecessarily exposed to potential adverse effects of these medications. ${ }^{15-17}$ The cost of these medications can be burdensome to the patient and taxing on the health system. ${ }^{15,18}$ Also, the cost implications are important to consider because of the potential for unnecessary 30-d readmission penalties due to the Medicare Hospital Readmissions Reduction Program. In addition, many hospitals participate in a COPD bundled payment program. Therefore, it is of utmost importance to establish an accurate COPD diagnosis.

The objective of this study was to explore the extent of COPD overdiagnosis at our institution and the effect it had on 30-d readmission rates.

\section{Methods}

This retrospective chart review was conducted at the Cleveland Clinic main campus, which is a 1,500-bed tertiary care hospital. The study was approved by our institutional review board, and informed consent was waived. Using our database, we identified all patients who were coded with a COPD hospital discharge in 2018. For our reporting purposes, COPD was defined as exacerbation (unspecified) or respiratory failure with a secondary diagnosis of COPD. The number of COPD admissions is continuously updated in this database, and the number of 30-d readmissions for those coded with a diagnosis of COPD is available daily.

The following demographic and clinical data were collected: age, gender, race, comorbidities, smoking status, body mass index, index stay, principal diagnosis, and 30-d readmission status. We also collected spirometry data (either historical or after hospitalization) to include $\mathrm{FEV}_{1}$ and FVC. Only those subjects who had spirometry data available were included in this analysis.

\section{QUICK LOOK}

\section{Current knowledge}

COPD is commonly overdiagnosed in patients, even when spirometry data are available. Those diagnosed with COPD can have a high readmission rate that is associated with poor outcomes and is part of the Medicare Hospital Readmissions Reduction Program. Overdiagnosing patients with COPD can lead to unintended worse outcomes in this population.

\section{What this paper contributes to our knowledge}

Inaccurately diagnosing COPD in patients may have a significant effect on the hospitalization and readmission rates for COPD. Hospitals should plan for patients who present with COPD to get spirometry to accurately document the presence of COPD. To our knowledge, this is the first study examining the impact that COPD overdiagnosis can have on 30-d hospital readmissions.

$\mathrm{FEV}_{1} / \mathrm{FVC}$ was compared with the predicted lower limit of normal values. To determine whether overdiagnosis increased 30-d readmission rates, we compared data in 4 groups: (1) all 30-d readmissions versus no $30-\mathrm{d}$ readmissions; (2) those who had $\mathrm{FEV}_{1} / \mathrm{FVC} \geq$ lower limit of normal versus those with a value $\geq 0.70$; (3) $30-d$ readmissions with a $\mathrm{FEV}_{1} / \mathrm{FVC}>$ lower limit of normal vs $\leq$ lower limit of normal; and (4) no 30-d readmissions with a $\mathrm{FEV}_{1} / \mathrm{FVC}>$ the lower limit of normal versus $\leq$ the lower limit of normal.

\section{Statistical Analysis}

Descriptive statistics were used to characterize the patient cohort. Demographic variables were described using mean \pm SD for continuous variables and counts with percentages for categorical variables. The 2-sample $t$ test or Wilcoxon rank sum test was used to compare continuous variables between the groups. The Fisher exact test or chisquare test with continuity correction were used to compare categorical variables. All analyses were performed at a significance level of .05. R 3.3.2 (R Foundation for Statistical Computing, Vienna, Austria) and SAS 9.3 (SAS Institute, Cary, North Carolina) were used for all analyses.

\section{Results}

In 2018, there were 523 COPD hospital discharges from Cleveland Clinic main campus. Of these, 99 patients did not have spirometry data available and were excluded from this analysis. The study therefore consisted of 424 subjects. Of the subjects who met the technical requirements for a 
Table 1. No 30-d Readmission vs 30-d Readmission*

\begin{tabular}{|c|c|c|c|c|c|c|c|}
\hline & \multicolumn{2}{|c|}{ Overall $(N=424)$} & \multicolumn{2}{|c|}{ 30-d Readmission $(n=100)$} & \multicolumn{2}{|c|}{ No 30-d Readmission $(n=324)$} & \multirow[b]{2}{*}{$P$} \\
\hline & $n$ & Variable & $n$ & Variable & $n$ & Variable & \\
\hline Age, y & 424 & $65.2 \pm 11.6$ & 100 & $66.5 \pm 10.4$ & 324 & $64.7 \pm 11.9$ & .28 \\
\hline Index length of stay, $d$ & 424 & $7.3 \pm 10.6$ & 100 & $8.3 \pm 10.2$ & 324 & $7.0 \pm 10.7$ & .18 \\
\hline Days to readmission, $\mathrm{d}$ & 100 & $13.7 \pm 8.0$ & 100 & $13.7 \pm 8.0$ & 0 & NA & \\
\hline Smoking history, pack-years & 299 & $31.3 \pm 26.2$ & 69 & $31.8 \pm 24.3$ & 230 & $31.2 \pm 26.8$ & .66 \\
\hline Body mass index, $\mathrm{kg} / \mathrm{m}^{2}$ & 424 & $30.5 \pm 10.1$ & 100 & $29.1 \pm 9.6$ & 324 & $31.0 \pm 10.2$ & .07 \\
\hline Gender & 422 & & 99 & & 323 & & .58 \\
\hline Female & & $250(59.2)$ & & $61(61.6)$ & & $189(58.5)$ & \\
\hline Male & & $172(40.8)$ & & $38(38.4)$ & & $134(41.5)$ & \\
\hline Race & 424 & & 100 & & 324 & & .048 \\
\hline African-American & & $214(50.5)$ & & $61(61.0)$ & & $153(47.2)$ & \\
\hline White & & $196(46.2)$ & & $36(36.0)$ & & $160(49.4)$ & \\
\hline Other & & $14(3.3)$ & & $3(3.0)$ & & $11(3.4)$ & \\
\hline Chronic kidney disease & 424 & $83(19.6)$ & 100 & $33(33.0)$ & 324 & $50(15.4)$ & $<.001$ \\
\hline Gastroesophageal reflux disease & 424 & $116(27.4)$ & 100 & $31(31.0)$ & 324 & $85(26.2)$ & .35 \\
\hline Atrial fibrillation & 424 & $91(21.5)$ & 100 & $29(29.0)$ & 324 & $62(19.1)$ & .036 \\
\hline Coronary artery disease & 424 & $171(40.3)$ & 100 & $45(45.0)$ & 324 & $126(38.9)$ & .28 \\
\hline Congestive heart failure & 424 & $76(17.9)$ & 100 & $21(21.0)$ & 324 & $55(17.0)$ & .36 \\
\hline Obstructive sleep apnea & 424 & $115(27.1)$ & 100 & $25(25.0)$ & 324 & $90(27.8)$ & .58 \\
\hline Principal diagnosis & 424 & & 100 & & 324 & & .65 \\
\hline Acute respiratory failure & & $138(32.5)$ & & $35(35.0)$ & & $103(31.8)$ & \\
\hline $\begin{array}{l}\text { COPD exacerbation and } \\
\text { lower respiratory infection }\end{array}$ & & $231(54.5)$ & & $50(5.0)$ & & $181(55.9)$ & \\
\hline COPD, unspecified & & $21(5.0)$ & & $6(6.0)$ & & $15(4.6)$ & \\
\hline Emphysema, unspecified & & $28(6.6)$ & & $9(9.0)$ & & $19(5.9)$ & \\
\hline Other emphysema & & $3(0.71)$ & & $0(0.0)$ & & $3(0.93)$ & \\
\hline Unspecified chronic bronchitis & & $3(0.71)$ & & $0(0.0)$ & & $3(0.93)$ & \\
\hline Smoking status & 332 & & 78 & & 254 & & .62 \\
\hline Current & & $73(22.0)$ & & $14(17.9)$ & & $59(23.2)$ & \\
\hline Former & & $236(71.1)$ & & $59(75.6)$ & & $177(69.7)$ & \\
\hline No & & $23(6.9)$ & & $5(6.4)$ & & $18(7.1)$ & \\
\hline
\end{tabular}

COPD overdiagnosis, 124 (29\%) had $\mathrm{FEV}_{1} / \mathrm{FVC}>$ lower limit of normal and $99(23.3 \%)$ had $\mathrm{FEV}_{1} / \mathrm{FVC}>.70$.

Overall, the cohort of 424 subjects was predominantly female. The average age was $65.2 \mathrm{y}$, and $50.5 \%$ were African-American. Most of the subjects were either current or prior smokers with a mean pack-year history of 31.3. Of the 100 subjects who were readmitted within $30 \mathrm{~d}$ of discharge, more had chronic kidney disease (33\% vs $15.4 \%$, $P=.01)$ and a history of atrial fibrillation (29\% vs $19.1 \%$, $P=.036)$. The mean index stay was also longer in the 30-d readmission group, but the difference was not significant ( 8.3 vs $7.0 \mathrm{~d}, P=.18$ ). The remaining baseline demographic and clinical data are presented in Table 1.

Of the 100 subjects who were readmitted, 35 had $\mathrm{FEV}_{1} / \mathrm{FVC}$ that was greater than their predicted lower limit of normal. Of the 324 subjects who were not readmitted within $30 \mathrm{~d}, 89(27.5 \%)$ had $\mathrm{FEV}_{1} / \mathrm{FVC}$ greater than the lower limit of normal. If the 35 readmitted subjects had not been coded with COPD, the $30-\mathrm{d}$ readmission rate would have decreased significantly from $23.6 \%$ to $16.7 \%$ (100 of 424 vs 65 of $389, P=.01)$. Even if all of the 124 subjects who had pulmonary function test data greater than the lower limit of normal had not been counted, the readmission rate would still have decreased from $23.6 \%$ to $21.7 \%$, but this difference was not significant (109 of 424 vs 65 of $300, P=.30$ ).

Using this same subject cohort, 21 of the 100 subjects who had a $30-\mathrm{d}$ readmission had $\mathrm{FEV}_{1} / \mathrm{FVC} \geq 0.70$. Of the 324 subjects who were not readmitted within $30 \mathrm{~d}, 78$ had $\mathrm{FEV}_{1} / \mathrm{FVC} \geq 0.70$. If the 21 readmitted subjects had not been coded as COPD, the 30-d readmission rate would have decreased from $23.6 \%$ to $19.6 \%$ (100 of 424 vs 79 of $403, P=.10$ ). If all of the 99 subjects who had $\mathrm{FEV}_{1} / \mathrm{FVC}$ $\geq 0.70$ had not been counted, the readmission rate would have increased from $23.6 \%$ to $24.3 \%$ (100 of 424 vs 79 of $325, P=.60)$. 


\section{COPD OverdiagnOSIS AND HOSPITAL READMISSION}

Table 2. $\mathrm{FEV}_{1} / \mathrm{FVC}$ Among Subjects With 30-d Readmission*

\begin{tabular}{|c|c|c|c|c|c|c|c|}
\hline & \multicolumn{2}{|c|}{ Overall $(n=100)$} & \multicolumn{2}{|c|}{$\begin{array}{c}\mathrm{FEV}_{1} / \mathrm{FVC}>\text { Lower } \\
\text { Limit of Normal }(n=35)\end{array}$} & \multicolumn{2}{|c|}{$\begin{array}{c}\mathrm{FEV}_{1} / \mathrm{FVC} \leq \text { Lower } \\
\text { Limit of Normal }(n=65)\end{array}$} & \multirow[b]{2}{*}{$P$} \\
\hline & $N$ & Variable & $n$ & Variable & $n$ & Variable & \\
\hline Age, y & 100 & $66.5 \pm 10.4$ & 35 & $68.8 \pm 12.1$ & 65 & $65.3 \pm 9.2$ & .06 \\
\hline Index length of stay, $d$ & 100 & $8.3 \pm 10.2$ & 35 & $5.3 \pm 3.5$ & 65 & $9.9 \pm 12.1$ & .18 \\
\hline Days to readmission, $\mathrm{d}$ & 100 & $13.7 \pm 8.0$ & 35 & $13.7 \pm 7.4$ & 65 & $13.7 \pm 8.4$ & .79 \\
\hline Smoking history, pack-years & 69 & $31.8 \pm 24.3$ & 24 & $32.4 \pm 26.7$ & 45 & $31.5 \pm 23.3$ & .91 \\
\hline Body mass index, $\mathrm{kg} / \mathrm{m}^{2}$ & 100 & $29.1 \pm 9.6$ & 35 & $31.0 \pm 10.6$ & 65 & $28.0 \pm 9.0$ & .14 \\
\hline Gender & 99 & & 35 & & 64 & & .85 \\
\hline Female & & $61(61.6)$ & & $22(62.9)$ & & $39(60.9)$ & \\
\hline Male & & $38(38.4)$ & & $13(37.1)$ & & $25(39.1)$ & \\
\hline Race & 100 & & 35 & & 65 & & .03 \\
\hline African-American & & $61(61.0)$ & & $27(77.1)$ & & $34(52.3)$ & \\
\hline White & & $36(36.0)$ & & $8(22.9)$ & & $28(43.1)$ & \\
\hline Other & & $3(3.0)$ & & $0(0.0)$ & & $3(4.6)$ & \\
\hline Chronic kidney disease & 100 & $33(33.0)$ & 35 & $15(42.9)$ & 65 & $18(27.7)$ & .12 \\
\hline Gastroesophageal reflux disease & 100 & $31(31.0)$ & 35 & $8(22.9)$ & 65 & $23(35.4)$ & .20 \\
\hline Atrial fibrillation & 100 & $29(29.0)$ & 35 & $18(51.4)$ & 65 & $11(16.9)$ & $<.001$ \\
\hline Coronary artery disease & 100 & $45(45.0)$ & 35 & $22(62.9)$ & 65 & $23(35.4)$ & .01 \\
\hline Congestive heart failure & 100 & $21(21.0)$ & 35 & $11(31.4)$ & 65 & $10(15.4)$ & .06 \\
\hline Obstructive sleep apnea & 100 & $25(25.0)$ & 35 & $10(28.6)$ & 65 & $15(23.1)$ & .55 \\
\hline Principal diagnosis & 100 & & 35 & & 65 & & .01 \\
\hline Acute respiratory failure & & $35(35.0)$ & & $19(54.3)$ & & $16(24.6)$ & \\
\hline $\begin{array}{l}\text { COPD exacerbation and } \\
\text { lower respiratory infection }\end{array}$ & & $50(5.0)$ & & $13(37.1)$ & & $37(56.9)$ & \\
\hline COPD, unspecified & & $6(6.0)$ & & $0(0.0)$ & & $6(9.2)$ & \\
\hline Emphysema, unspecified & & $9(9.0)$ & & $3(8.6)$ & & $6(9.2)$ & \\
\hline Smoking status & 78 & & 29 & & 49 & & .59 \\
\hline Current & & $14(17.9)$ & & $5(17.2)$ & & $9(18.4)$ & \\
\hline Former & & $59(75.6)$ & & $21(72.4)$ & & $38(77.6)$ & \\
\hline No & & $5(6.4)$ & & $3(10.3)$ & & $2(4.1)$ & \\
\hline \multicolumn{8}{|c|}{$\begin{array}{l}\text { Data are presented as mean } \pm \text { SD or } n(\%) \text {. } \\
* \text { Table } 2 \text { excludes subjects without spirometry data. } \\
\mathrm{NA}=\text { not applicable }\end{array}$} \\
\hline
\end{tabular}

Subjects who had a $30-\mathrm{d}$ readmission $(n=100)$ were divided into 2 groups: $\mathrm{FEV}_{1} / \mathrm{FVC} \leq$ the lower limit of normal $(n=65)$ versus $\mathrm{FEV}_{1} / \mathrm{FVC}>$ the lower limit of normal $(n=35)$ (Table 2). Like the first group compared, most were female (60\% vs $62.9 \%, P=.85$ ), elderly (mean age 65.3 vs 68.8 y, $P=.06$ ), and African-American (52.3\% vs $77.1 \%, P=.033)$. Many were former or current smokers ( $96 \%$ vs $89.6 \%, P=.59$ ) and had a mean pack-year history of 31.5 and $32.4(P=.91)$, respectively. Significant differences in comorbidities were seen in those with a history of atrial fibrillation $(16.9 \%$ vs $51.4 \%, P=.01)$ and coronary artery disease $(35.4 \%$ vs $62.9 \%, P=.01)$. Another significant difference was seen in the subjects with a principal diagnosis of COPD exacerbation with or without acute lower respiratory infection $(56.9 \%$ vs $37.1 \%, P=.01)$ and acute respiratory failure $(24.6 \%$ vs $54.3 \%, P=.01)$. Although body mass index was greater in the group with $\mathrm{FEV}_{1} / \mathrm{FVC}$ $>$ lower limit of normal (mean 31 vs $28, P=.14$ ), it was not a statistically significant difference. The length of index stay for both groups was 9.9 versus $5.3 \mathrm{~d}(P=.18)$.

The third group analyzed consisted of those who did not have a $30-d$ hospital readmission $(n=324)$ (Table 3). In this group, we compared those who had $\mathrm{FEV}_{1} / \mathrm{FVC} \leq$ lower limit of normal $(n=235)$ with those with $\mathrm{FEV}_{1} / \mathrm{FVC}>$ lower limit of normal $(n=89)$. Like the other two groups compared, most were female (57.9\% vs $60.2 \%, P=.70)$. Unlike the others, although both groups were elderly (mean age 65.8 vs $61.9 \mathrm{y}, P=$ .004), the difference in age was statistically significant. Both groups had a high percentage of smoking history $(94.9 \%$ vs $88.1 \%, P=.06)$, and the mean pack-year history was statistically significant (34.5 vs $23.1, P=.01$ ). 


\section{COPD OverdiagnOSIS AND HOSPITAL READMISSION}

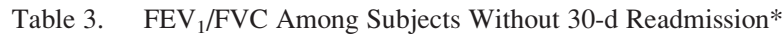

\begin{tabular}{|c|c|c|c|c|c|c|c|}
\hline & \multicolumn{2}{|c|}{ Overall $(n=324)$} & \multicolumn{2}{|c|}{$\begin{array}{c}\mathrm{FEV}_{1} / \mathrm{FVC}>\text { Lower } \\
\text { Limit of Normal }(n=89)\end{array}$} & \multicolumn{2}{|c|}{$\begin{array}{c}\mathrm{FEV}_{1} / \mathrm{FVC} \leq \text { Lower } \\
\text { Limit of Normal } \\
(n=235)\end{array}$} & \multirow[b]{2}{*}{$P$} \\
\hline & $N$ & Variable & $n$ & Variable & $n$ & Variable & \\
\hline Age, y & 324 & $64.7 \pm 11.9$ & 89 & $61.9 \pm 13.2$ & 235 & $65.8 \pm 11.3$ & .004 \\
\hline Index length of stay, $d$ & 324 & $7.0 \pm 10.7$ & 89 & $7.6 \pm 6.0$ & 235 & $6.8 \pm 12.0$ & $<.001$ \\
\hline Smoking history, pack-years & 230 & $31.2 \pm 26.8$ & 66 & $23.1 \pm 22.1$ & 164 & $34.5 \pm 27.9$ & .001 \\
\hline Body mass index, $\mathrm{kg} / \mathrm{m}^{2}$ & 324 & $31.0 \pm 10.2$ & 89 & $35.6 \pm 12.7$ & 235 & $29.2 \pm 8.5$ & $<.001$ \\
\hline Gender & 323 & & 88 & & 235 & & .70 \\
\hline Female & & $189(58.5)$ & & $53(60.2)$ & & $136(57.9)$ & \\
\hline Male & & $134(41.5)$ & & $35(39.8)$ & & $99(42.1)$ & \\
\hline Race & 324 & & 89 & & 235 & & .40 \\
\hline African-American & & $153(47.2)$ & & $45(50.6)$ & & $108(46.0)$ & \\
\hline White & & $160(49.4)$ & & $43(48.3)$ & & $117(49.8)$ & \\
\hline Other & & $11(3.4)$ & & $1(1.1)$ & & $10(4.3)$ & \\
\hline Chronic kidney disease & 324 & $50(15.4)$ & 89 & $14(15.7)$ & 235 & $36(15.3)$ & .93 \\
\hline Gastroesophageal reflux disease & 324 & $85(26.2)$ & 89 & $19(21.3)$ & 235 & $66(28.1)$ & .22 \\
\hline Atrial fibrillation & 324 & $62(19.1)$ & 89 & $25(28.1)$ & 235 & $37(15.7)$ & .01 \\
\hline Coronary artery disease & 324 & $126(38.9)$ & 89 & 37 (41.6) & 235 & $89(37.9)$ & .54 \\
\hline Congestive heart failure & 324 & $55(17.0)$ & 89 & $19(21.3)$ & 235 & $36(15.3)$ & .20 \\
\hline Obstructive sleep apnea & 324 & $90(27.8)$ & 89 & 37 (41.6) & 235 & $53(22.6)$ & $<.001$ \\
\hline Principal diagnosis & 324 & & 89 & & 235 & & $<.001$ \\
\hline Acute respiratory failure & & $103(31.8)$ & & $53(59.6)$ & & $50(21.3)$ & \\
\hline $\begin{array}{l}\text { COPD exacerbation and } \\
\text { lower respiratory infection }\end{array}$ & & $181(55.9)$ & & $31(34.8)$ & & $150(63.8)$ & \\
\hline COPD, unspecified & & $15(4.6)$ & & $0(0.0)$ & & $15(6.4)$ & \\
\hline Emphysema, unspecified & & $19(5.9)$ & & $4(4.5)$ & & $15(6.4)$ & \\
\hline Other emphysema & & $3(0.93)$ & & $1(1.1)$ & & $2(0.85)$ & \\
\hline Unspecified chronic bronchitis & & $3(0.93)$ & & $0(0.0)$ & & $3(1.3)$ & \\
\hline Smoking status & 254 & & 76 & & 178 & & .06 \\
\hline Current & & $59(23.2)$ & & $21(27.6)$ & & $38(21.3)$ & \\
\hline Former & & $177(69.7)$ & & $46(60.5)$ & & 131 (73.6) & \\
\hline No & & $18(7.1)$ & & $9(11.8)$ & & $9(5.1)$ & \\
\hline
\end{tabular}

Data are presented as mean $\pm \mathrm{SD}$ or $n(\%)$.

*Table 3 excludes subjects without spirometry data.

Comorbidities of statistical significance were diabetes (28.1\% vs $52.8 \%, P=.01$ ), obstructive sleep apnea $(22.6 \%$ vs $41.6 \%, P=.01)$, and atrial fibrillation $(15.7 \%$ vs $28.1 \%, P=.01)$. Similar to the second group, there was a significant difference in the subjects with a principal diagnosis of COPD exacerbation with or without acute lower respiratory infection $(63.8 \%$ vs $34.8 \%$, $P=.01$ ) as well as body mass index (mean 29.2 vs 35.6, $P=.01)$. Lastly, another significant difference was seen in the length of index stay (mean 6.8 vs $7.6 \mathrm{~d}, P=.01$ ).

\section{Discussion}

In this retrospective study of subjects discharged with a diagnosis of COPD, we found that COPD was overdiagnosed in hospitalized subjects based on spirometry data. This was true whether using the standard of $\mathrm{FEV}_{1} / \mathrm{FVC}<0.70$ or the lower limit of normal. This is consistent with the literature and extends what is known on this topic by also examining the impact this can have on 30-d hospital readmissions.

The Medicare Hospital Readmissions Reduction Program is well-intended and has led us at Cleveland Clinic to develop an integrated program to care for these individuals. ${ }^{19} \mathrm{It}$ allows for the increased allocation of resources for the care of the hospitalized COPD patient after discharge. ${ }^{7}$ While we are focused on improving this care, we sometimes lose sight that the COPD diagnosis may not be accurate. As such, there may be unintended treatment outcomes. To our knowledge, this is the first attempt to compare the accuracy of a COPD diagnosis with a 30-d hospital readmission group. This was also the first to compare the characteristics and differences seen between these groups.

Although there are many factors besides spirometry to consider when making a COPD diagnosis, it is still 
considered the gold standard. GOLD recommends using a post-bronchodilator $\mathrm{FEV}_{1} / \mathrm{FVC}<0.70$ to confirm the COPD diagnosis. Because the GOLD standard of $<0.70$ has a greater potential for overdiagnosis, we chose to use lower limit of normal for this study. This was also based on recommendations made by the American Thoracic Society/European Respiratory Society and others in the field. ${ }^{20}$ Many others advocate using the lower limit of normal standard because the GOLD standard can lead to misclassification of COPD, especially when used in an elderly population, as is often seen with COPD. ${ }^{21-23}$

A number of our subjects diagnosed with COPD did not have spirometry data in their records. In fact, the incidence of not having spirometry on record can be rather high. ${ }^{9,11,12,14-16,18,24}$ Because of this, we strongly advocate for spirometry to be performed with every patient suspected of having COPD, consistent with the GOLD guidelines, to confirm this diagnosis.

COPD overdiagnosis or false positive diagnosis has been reported in the literature. ${ }^{12-14}$ The Burden of Obstructive Lung Disease (BOLD) study reported a $48.5 \%$ false positive COPD diagnosis in the Austrian group ${ }^{15}$ and a $62 \%$ false positive diagnosis overall. ${ }^{17}$ The overdiagnosis in the E-DIAL study was $13.1 \% .{ }^{16}$ In our group, the rate of overdiagnosis was $29 \%$ in the lower limit of normal group and $23.3 \%$ in the $\geq 0.70$ group. Although we recognize that COPD is vastly underdiagnosed and that screening should take place per GOLD guidelines, our results illustrate the caution providers should use when making the diagnosis.

Our study indicated that providers were more likely to make the COPD diagnosis with or without lower respiratory infection diagnosis in the acute care hospital setting in subjects with $\mathrm{FEV}_{1} / \mathrm{FVC} \leq$ the lower limit of normal than in those with $\mathrm{FEV}_{1} / \mathrm{FVC}>$ the lower limit of normal. This is encouraging because there are many conditions that can present with similar symptoms, making an accurate diagnosis difficult. The Spiromics Group ${ }^{25}$ reported that current or former smokers who were symptomatic even with preserved lung function were more likely to have a previous COPD diagnosis than those who were nonsmokers and asymptomatic. Because our subjects had such a high incidence of current or smoking history, this may have contributed to the overdiagnosis of COPD. Also, subjects with acute respiratory failure and a secondary diagnosis of COPD were much more prevalent in the $\mathrm{FEV}_{1} / \mathrm{FVC}>$ lower limit of normal group. Although COPD may not have been the cause of the index admission, these subjects were still considered COPD discharges and thus were exposed to the possibility of being reported as a 30-d hospital readmission because it is all-cause.

Interestingly, in those subjects who did not have a 30-d readmission, there was a significant reduction in pack-year smoking history in the group with $\mathrm{FEV}_{1} / \mathrm{FVC}>$ lower limit of normal versus those with $\mathrm{FEV}_{1} / \mathrm{FVC} \leq$ lower limit of normal. Although there was a reduction, the number was still high (mean $23.1 \pm 34.5$ pack-years). There are also cardiac symptoms that can present similarly to COPD, which may cause misdiagnosis and overestimation. ${ }^{26}$ In our group that did not have a 30-d readmission, there was a significant increase in atrial fibrillation, coronary artery disease, and congestive heart failure in the group with $\mathrm{FEV}_{1} / \mathrm{FVC}>$ lower limit of normal versus those with $\mathrm{FEV}_{1} / \mathrm{FVC} \leq$ lower limit of normal. These associated symptoms may have led to an overdiagnosis in the patients whose spirometry did not support the COPD diagnosis. This false positive diagnosis was also seen in the BOLD group. ${ }^{17}$ Others have described an increased risk of overdiagnosis in females, current smokers, and those who have a higher body mass index. ${ }^{24}$ This is applicable in our subject cohort and may contribute to the overdiagnosis of COPD. The majority of our subjects were female, many were current or former smokers, and many had an increased body mass index. In fact, increased body mass index was seen in our subjects with spirometry $>$ lower limit of normal and was statistically significant in the group that did not have a 30-d hospital readmission $(P=.01)$.

Our study has limitations. First, we chose a convenience sample of subjects discharged from our hospital in the calendar year 2018 only. Second, it is a single-center study, so the results may not be generalizable. Multi center studies are therefore warranted. Finally, this is a retrospective chart review, and data may be missing, including data from other health care systems. For example, we had access to spirometry data mainly performed within our health system and recorded in the subject's medical record. Subjects may have had testing at another out-patient clinic that was not available for this review. Spirometry also was not performed at a standardized time frame; some subjects underwent testing before hospitalization and some after. We also used the $\mathrm{FEV}_{1} / \mathrm{FVC}>$ lower limit of normal standard instead of the current GOLD-recommended $\mathrm{FEV}_{1} / \mathrm{FVC}<$ 0.70 standard. Our cohort revealed that overdiagnosis existed when applying each spirometry standard, although it was greater in the lower limit of normal group.

\section{Conclusions}

COPD was overdiagnosed in our cohort of subjects; this was true whether the standard was $\mathrm{FEV}_{1} / \mathrm{FVC}<0.70$ or $\mathrm{FEV}_{1} / \mathrm{FVC}>$ the lower limit of normal. Furthermore, this overdiagnosis artificially inflated the $30-\mathrm{d}$ readmission rate. These results illustrate the caution that providers should use when making a COPD diagnosis.

\section{REFERENCES}

1. Sullivan J, Pravosud V, Mannino DM, Siegel K, Choate R, Sullivan T. National and state estimates of COPD morbidity and mortality- United States, 2014-2015. Chronic Obstr Pulm Dis 2018;5(4):324-333. 


\section{COPD OverdiagnOSIS AND HOSPITAL READMISSION}

2. Gershon AS, Warner L, Cascagnette P, Victor JC, To T. Lifetime risk of developing chronic obstructive pulmonary disease: a longitudinal population study. Lancet 2011;378(9795):991-996.

3. Buist AS, McBurnie MA, Vollmer WM, Gillespie S, Burney P, Mannino DM, et al. International variation in the prevalence of COPD (the BOLD study): a population-based prevalence study. Lancet 2007;370(9589):741-750.

4. Ford ES, Murphy LB, Khavjou O, Giles WH, Holt JB, Croft JB. Total and state-specific medial and absenteesim costs of COPD among adults aged greater than 18 years in the United States for 2010 and projections through 2020. Chest 2015;147(1):31-45.

5. Shah T, Press V, Huisingh-Scheetz M, White SR. COPD readmissions: addressing COPD in the era of value-based health care. Chest 2016;150(4):916-926.

6. Almagro P, Calbo E, Ochoa de Echagüen A, Barreiro B, Quintana S, Heredia JL, Garau J. Mortality after hospitalization for COPD. Chest 2002;121(5): 1441-1448.

7. McIlvennan CK, Eapen ZJ, Allen LA. Hospital readmissions reduction program. Circ J 2015;131(20):1796-1803.

8. Global Initiative for Chronic Obstructive Lung Disease (GOLD). Global Strategy for the Diagnosis, Management and Prevention of chronic obstructive pulmonary disease: 2019 Report. Available at: http://www.goldcopd.org. Accessed June 3, 2020.

9. Hangaard S, Helle T, Nielsen C, Hejlesen OK. Causes of misdiagnosis of chronic obstructive pulmonary disease: a systematic scoping review. Respir Med 2017;129:63-84.

10. Gershon AS, Hwee J, Chapman KR, Aaron SD, O'Donnell DE, Stanbrook MB, et al. Factors associated with undiagnosed and overdiagnosed COPD. Eur Respir J 2016;48(2):561-564.

11. Chapman KR, Tashkin DP, Pye DJ. Gender bias in the diagnosis of COPD. Chest 2001;119(6):1691-1695.

12. Jain VV, Allison DR, Andrews S, Mejia J, Mills PK, Peterson MW. Misdiagnosis among frequent exacerbators of clinically diagnosed asthma and COPD in absence of confirmation of airflow obstruction. Lung 2015;193(4):505-512.

13. Bourbeau J, O’Donnell D, Maltais F, Marciniuk D, Benedetti A, Aaron S. What are the factors related to misdiagnosis of COPD? Eur Respir J 2014;38(Suppl 55):p261.

14. Spero K, Bayasi G, Beaudry L, Barber KR, Khorfan F. Overdiagnosis of COPD in hospitalized patients. Int J Chron Obstruct Pulmon Dis 2017;12:2417-2423
15. Lamprecht B, Mahringer A, Soriano J, Kaiser B, Buist AS, Studnicka M. Is spirometry properly used to diagnose COPD? Results from the BOLD study in Salzburg, Austria: a population-based analytical study. Prim Care Respir J 2013;22(2):195-200.

16. Nardini S, Annesi-Maesano I, Simoni M, del Ponte A, Sanguinetti $\mathrm{CM}$, De Benedetto F. Accuracy of diagnosis of COPD and factors associated with misdiagnosis in primary care setting. E-DIAL (Early DIAgnosis of obstructive lung disease) study group. Respir Med 2018;143:61-66

17. Sator L, Horner A, Studnicka M, Lamprecht B, Kaiser B, McBurnie MA, et al. Overdiagnosis of COPD in subjects with unobstructed spirometry: a BOLD analysis. Chest 2019;156(2):277-288

18. Miller MR, Levy ML. Chronic obstructive pulmonary disease: missed diagnosis versus misdiagnosis. BMJ 2015;351:h3021

19. Russo AN, Sathiyamoorthy G, Lau C, Saygin D, Han X, Wang X-F, et al. Impact of a post-discharge integrated disease management program on COPD hospital readmissions. Respir Care 2017;62(11):13961402.

20. Ruppel GL, Carlin BW, Hart M, Doherty DE. Office spirometry in primary care for the diagnosis and management of COPD: national lung health education program update. Respir Care 2018;63(2):242-252.

21. Swanney MP, Ruppel G, Enright PL, Pedersen OF, Crapo RO, Miller $\mathrm{MR}$, et al. Using the lower limit of normal for the $\mathrm{FEV}_{1} / \mathrm{FVC}$ ratio reduces the misclassification of airway obstruction. Thorax 2008;63 (12):1046-1051.

22. Miller MR, Quanjer PH, Swanney MP, Ruppel G, Enright PL. Interpreting lung function data using $80 \%$ predicted and fixed thresholds misclassifies more than 20\% of patients. Chest 2011;139(1):5259.

23. Culver BH. How should the lower limit of normal range be defined? Respir Care 2012;57(1):136-145.

24. Arne M, Lisspers K, Ställberg B, Boman G, Hedenström H, Janson C, Emtner M. How often is diagnosis of COPD confirmed with spirometry? Respir Med 2010;104(4):550-556.

25. Woodruff PG, Barr RG, Bleecker E, Christenson SA, Couper D, Curtis JL, et al. Clinical significance of symptoms in smokers with preserved pulmonary function. N Engl J Med 2016;374(19):18111821.

26. Hawkins NM, Petrie MC, Jhund PS, Chalmers GW, Dunn FG, McMurray J. Heart failure and chronic obstructive pulmonary disease: diagnostic pitfalls and epidemiology. Eur J Heart Fail 2009;11(2):130139.

This article is approved for Continuing Respiratory Care Education credit. For information and to obtain your CRCE

(free to AARC members) visit

www.rcjournal.com

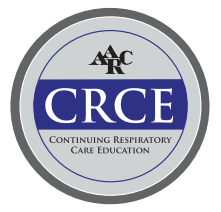

